\title{
Compact shelving of circulating collections
}

\author{
By Sherrie Sam and Jean A. Major
}

\section{Space savers please library users}

$\mathrm{n}$ the process of planning a building addi-

tion and renovation at the University of Mississippi, library personnel began to consider selective use of compact shelving to maximize the available funding for the project. The published record of exploration and use of compact shelving is nearly unanimous in identifying one significant limitation: while some kinds of materials are well suited to storage in compact shelving, heavily used parts of the collection are thought to be less appropriate because compact shelving limits their accessibility. Users have difficulty browsing and sometimes must wait for access to the specific range in which they are interested.

Nonetheless, indications are that such use is growing. In a 1987 survey of academic libraries using compact shelving in public access areas, 17 of the 21 respondents had installed the shelving within the previous five years-that is, since $1982 .^{2}$

In the summer of 1989 the library at the University of Mississippi (UM) installed compact shelving as a stopgap to house 60,000 70,000 volumes of circulating books, and the installation is regarded as successful by librarians and users. This apparent success provided encouragement for the library to plan for increased use of compact shelving after the construction project. The present study resulted from the anticipation of additional and, possibly, a wider variety of uses. Specifically, two fundamental questions needed exploration: can circulating books be housed in compact shelving? and what level of use constitutes "heavily used" or "high-use" materials which would not be suitable? Secondarily, the existing shelving offered a chance to experiment with several kinds of data collection and analysis to support this particular decision. To investigate these questions, data were gathered to make a detailed description of the specific characteristics of the library's present use of compact shelving housing a circulating collection.

The present mechanical-assist compact shelving installation at UM consists of 2430 foot ranges with four aisles. The collection is made up of circulating books in a group of classifications considered to be low-use in this library: A, C, G, L, M, S, and Z. Of these, the greatest number are Ls (about 20,000 volumes), with substantial collections of Gs and Zs (about 7,500 volumes each). Other parts of this collection are very small.

The following kinds of data were examined for this investigation:

Circulation Statistics. Loans of books in each classification were tabulated for the month of April for four years-1988 and 1989 (before installation of compact shelving) contrasted with 1990 and 1991 (after installation). Within these tabulations, totals by class, grand totals, daily averages, and hourly averages were computed.

User Responses. From April 23 through May 14,1991 , brief survey forms were made available for users to communicate their experiences with the compact shelving. They were asked to indicate the classification letter sought, whether they had to wait to get into the appropriate aisle, and if the shelves were easy to use. Totals and percentages were reported.

Shelvers' Notes. Shelvers filled out tally sheets for each hour of shelving in the compact section during the period from April 22 through 
May 2, 1991. Each shelver indicated the number of books shelved, the number and duration of interruptions to permit user access, and any observations they wished to make.

\section{Findings}

Circulation for the collection included in this study comprised from six to eight percent of the library's total circulation for the years in question, and the share fluctuated insignificantly within that range over time. The affected collection did not show a noticeable fall-off in circulation after the installation of compact shelving, nor did its use increase dramatically.

The Morris study categorized high use as an installation with more than 100 uses per week. Only five respondents in that survey had installations of more than 100 double-faced sections, used more than 100 times per week. ${ }^{3}$ UM's installation has 240 double-faced sections. In April of the last four years average weekly circulation ranged from 210 to 630 - clearly high use. During the busiest year in the study (1990), the collection housed in compact shelving had circulations at the average rate of seven per hour. For perspective, these data were collected during the last month of the spring semester, the busiest time of the year.

Users who elected to fill out surveys-only 25 during a three-week period-were using all parts of the collection. A notable majority (76\%) did not have to wait for an aisle to become available, and the same percentage reported finding the shelves easy to use. For those who had to wait for access to an aisle, the reported wait averaged less than one minute.

The traffic in the compact shelving section is low, according to the data sheets submitted by 13 shelvers. Most shelvers experienced no more than one or two interruptions per hour. The shelvers estimated their interruptions to be about five minutes each, while the users felt that they had to wait less then a minute for access to an aisle.

\section{Conclusions}

The two questions which inspired this study are, "Can circulating books be housed in compact shelving?" and "What level of use constitutes 'heavily used' or 'high-use' materials which would not be suitable?" The data collected in this brief investigation provide positive answers to both questions.

- A large shelving installation with seven circulations per hour or more than 600 per week is not too heavily used for satisfactory public access.

- Most users are quite satisfied with the shelving, as the following remarks illustrate:

"I love moving the shelves around to fit in the row I need. More of the library should be like this."

"I like them," and "It's pretty cool."

"Very useful, spacesaving, and efficient. Bravo!!"

The dissenters also responded, though:

"I got stuck between the shelves" and "I was almost squeezed between shelves."

"Do not expand this form of shelving upstairs. Disaster will ensue. Patrons will not respond favorably. Locating material will become much more time-consuming."

"There was an unsupervised child treating the shelves like toys!"

- The perceived wait for a user's access to an aisle was very brief; users reported waiting less than a minute.

- Installation of compact shelving has no effect on the level of circulation of the collection housed within it.

- Each shelver might work on two trucks of books at a time so that one will be available if a user causes an interruption in shelving from the other.

- Detailed circulation statistics make a satisfactory way to identify parts of a library's collection which are suitable to be housed in compact shelving because of the level of their use. Useful checks after installation are a brief user survey and/or collecting comments from shelvers.

\section{Notes}

${ }^{1}$ See, for example, Evan I. Farber, "Compact shelving in smaller libraries" Library Issues 7 , no. 5 (May 1987): 3; Keyes D. Metcalf, Planning Academic and Research Library Buildings, $2 d$ ed., by Philip D. Leighton and David C. Weber (Chicago: American Library Association, 1986), p. 166; Michael Gorman, "Moveable compact shelving: The current answer," Library Hi Tech 20 (Winter 1987): 26; and Franklyn F. Bright, Planning for a Movable Compact Shelving System, Library Administration and Management Association Occasional Papers Series, no. 1 (Chicago: American Library Association, 1991), p. 5.

${ }^{2}$ Leslie R. Morris and Frank M. Webster, "Public use of compact shelving," Collection Management 10 , nos. 1/2 (1988): 124-25.

IIbid., 127. 